\section{Festival Reviews}

Bellingham ElectronicArts Festival (BEAF)

November 30 - December 3, 2006,

Bellingham, WA

by Facob Gotlib

There's a famous scene in the movie Austin Powers where Mike Myers is laying in bed with a woman who asks him to describe himself in a nutshell, and he suddenly exclaims, "Help! I'm in a nutshell! How did I get into this nutshell?" We composers doubtless ask ourselves this question often; we al have nutshells in which we exist, small niches or scenes that are subdivisions of the greater musical world. And within these musical gated communities reside composers, performers, theories, philosophies, histories, and even audiences - what more could one possibly need? It's easy to see why many of us never leave the comforts of our homes, be they "classical," "electronic," "experimental," or any of the infinitely small subgenres within each. However just as a person who doesn't stray far from home can never get an idea of the vastness and wonder of the world, neither can a musician that fails to venture outside his or her self-prescribed niche see the beauty of the broader musical universe.

Enter the Bellingham Electronic Arts Festival (or BEAF), whose goal was to take everyone working with electronic media out of their cushy artistic suburbias, and place them all in a giant mixed-income neighborhood in the middle of the city. The festival brought together artists from all over the world, from nearly every scene or niche in the electronic music community (excluding most popular dance genres). Academics, pop musicians, DJs, $\mathrm{VJs}$, dancers, installation artists, laptop improvisers, turntablists, and many more met and mingled for four days of concerts, lectures, and parties. No one got shot (to my knowledge), but many minds were doubtless blown.

BEAF displayed its raison d'etre brilliantly in the Opening Gala Concert held at the American Museum of Radio and Electricity. The works ranged from ambient noise pieces to techno-pop performances to experimental improvisations to academic electroacoustic music. From the start, BEAF unveiled its secret weapon: talented video artist Peter Rand, who performed live video improvisations to many of the works, both on this concert and all the others at BEAF. Scott Smallwood began the concert with an impressive set of ambient noise improvisation, displaying subtly changing textures of static and distortion that, while often soothing, were continually thrilling to hear. Jeff Morris's Improvisation, while more firmly rooted in academic electronic music, was equally as evocative with its wide variety of sound sources and quick pace. Ligyro, a group from Bloomington, IN, changed things up with a set of electropop/rock songs, featuring the sole usage of human vocals on the entire concert. Their music was exceptionally broad, ranging from more up-tempo dancey tunes to mellower, more ruminative pieces, showcasing the expressive voice of Neil Cain. The centerpiece of this concert, however, was the nearly evening-long Six Axioms by Randy Jones. The work featured interactive synthesis and video that the composer controlled with an instrument called a "radio drum," which operated like a combination sensor and drum pad. The visual and sonic textures in this piece were gorgeous, and though it was lengthy, the consistently meditative mood created a hypnotic and ethereal space. The interaction between the music and Jones's gestures were engaging to watch, often giving the impression that the sounds were controlling Jones as much as he was controlling them. This opening concert, as the rest of the festival, provided a space where arbitrary divisions of "scenes" and "styles" were completely obliterated.

Throughout the next three days, the concerts were programmed by particular style, i.e. "Sonic Explorations (experimental)," "Intersections (immersive electroacoustic)," "Rhythm \& Noise (postindustrial)," etc. The shows took place in a variety of venues around Bellingham, from the gorgeous (but freezing) American Museum of Radio and Electricity, to the Western Washington University concert hall, to the Nightlight Lounge, a rock club downtown. Sebastian Roux delivered a blistering, noisy set that achieved beauty and intensity through its sheer variety of sound sources and treatments; its relentless energy and thrilling movements were a perfect bridge between academic electroacoustic music and more popular experimental styles. Rocco Di Pietro's Deconstructed Fountain From Ravel With Derrida Watching for piano and tape was mysterious and intriguing, with both piano and tape parts slowly expanding and blooming like a flower. Lusine (aka Jeff McIlwain) presented subtly textured ambiences, creating an entrancing yet always rich and fascinating atmosphere. Chris Biggs's Inconspicuous Impulses for piano and tape attempted to reconcile the "contradictory tendencies" of electronic and serial music. Though I'm not sure if I noticed these contradictions, the rich counterpoint and Davidovsky-esque interactions between the performer and the tape, as well as the virtuosic performance by Shu-ching Cheng, made for a captivating listening experience.

BEAF's guest lecturer this year was Barry 
Truax, a composer and professor at Simon Fraser University in Vancouver. Truax gave a fascinating lecture on the history and philosophy of Soundscape composition and Acoustic Ecology, or the idea that recordings of a particular space's environment yields not only material for composition but an auditory "snapshot" of a place, and that by comparing recordings of a single location over the course of many years, we can learn about how it has been changed and affected. Truax presented several of his works throughout the festival, including Island, a mesmerizing piece that uses techniques of soundscape composition to take the listener on a journey through the landscape of an imaginary island. The octophonic presentation of the work created an immersive world that once again had ties to classical electroacoustic music and to more popular ambient styles.

Some of the strongest, most engaging music at BEAF came from the live/interactive performances. Kinesthetech Sense, a multimedia dance group from the Bay Area, lectured and performed a thrilling work for electronic music, interactive video, and dance called FleshLightMovement. TrioMetrik, another group from the Bay Area, weathered technical difficulties and delivered an engaging set using Zeta instruments, acoustic sounds, and gorgeous interactive video featuring image synthesis, paintings, and text. Both TrioMetrik and Kinesthetech Sense created an electronic network of visual and sonic elements, all linked via computer, to express a kind of information synesthesia where aural senses were mapped to visual ones, which were mapped to bodily ones, and back again.

Perhaps the strongest performer at the festival, however, was Prefuse 73 (aka Scott Herren). Somewhat of a star in the experimental hip-hop world, Herren and his performing partner (whose name was not listed) performed their brand of dense, eclectic, textural music to the largest crowd of the entire festival. Manipulating turntables, samplers, drum machines, and computers, Prefuse's set was not only musicallyexciting, buttheperformanceitself was easily the most energetic and engaging of the entire festival. This was no sittingcalmly-behind-a-laptop performance: the duo was constantly moving their hands (and feet) across a sea of electronic gear, heads bobbing with the music, eyes locked in concentration, even actual sweat pouring down their brows. Many listeners claim electronic music is boring to experience in performance because the performers hardly do anything; Prefuse 73 would easily prove them wrong, delivering one of the most exciting, interactive, and human electronic performances I have ever seen.

Aside from the eclectic music, the one thing that made this festival stand out from any that I've been to before or since was the audience. At every concert (even the electroacoustic ones), there was a nearly full audience of both composers and "civilians" - open-minded music lovers who were not professional musicians. After attending countless new music festivals that were populated entirely by composers and academics, to see a general audience that was excited and enthusiastic about this music was thrilling. Bruce Hamilton and his staff did an amazing job not only organizing and overseeing a festival as extensive as this one, but for setting a new precedent for contemporary music festivals. If contemporary classical music (including electroacoustic music) is to thrive, it becomes imperative that we as composers break out of our nutshells, and start interacting and coexisting with our colleagues in other fields (including more "popular" ones). BEAF, and similar festivals like it, is a breath of fresh air and a bold step in the right direction.

\section{NWEAMO Festival}

Morelia, Mexico,

\section{September 19, 200}

by Jerónimo Rajchenberg

In the Purepecha lands in the central plateau of Mexico is Morelia, a calm city with a large music tradition. One of Mexico's most important music conservatories, the Conservatorio de las Rosas, has been there since 1743. Yet the music landscape in Morelia has been traditional and, somehow, conservative. should say that in Mexico contemporary music and technology music concerts have rarely a crowded audience. That is why it was so surprising and interesting to see the NWEAMO concerts and the reaction and acceptance of the audience.

Concerts took place at the CMMAS (Mexican Center for Music and Sonic Arts), a technology art center directed by Rodrigo Sigal that allows instrumentalists, composers, video and installation artists to meet and work in a creative and rich environment.

First of all, it was striking to see the concert hall filled to capacity. Not only were all the seats taken, but there were also people standing here and there, listening with attention throughout the entire concert. The CMMAS received more and more people every day - all kinds of people, from experts in technology and art to people who came for the very first time to know this thing called contemporary musical art.

In the NWEAMO festival, the music of twelve composers was presented, with a very large range of aesthetic and technological approaches, from a cello piece (the traditional all-written-in-ascore) to the dance-video-cello-computer music proposal of Kinesthetech Sense. All of them performed over a four-channel speaker system array. I'd like to write about the pieces and performances that 
have contributed, from my point of view, to the Mexican music scene.

Le Repas du Serpent, by Mexican composer Javier Alvarez and vigorously performed by cellist Iracema Andrade, was the first piece in the festival to create a multimedia ambiance, including cello played in very different ways, computer sounds and video. The video of Le Repas du Serpent is an old French recording of a snake eating a rabbit. It must be in a zoo or a biology class, because we can see people looking at the snake. It is as interesting to see the snake eating the rabbit as it is to see the reactions of the people in the video. The piece has a delicious variety and development of timbre, and spatialization that locks in music the audience's attention. The cello performs several glissandi, to which the tape responds with changes in the size of grains. The tape's sound's texture, then, changes in a glissando way, creating a dialogue between them.

Another very interesting work was the one presented by Mexican-Dutch group Presidentes con Bigote (Presidents with Moustache), created by Carlos Iturralde and Keir Neuringer playing several instruments and sound devices. The first piece they performed was a very surprising guitar-sax-tape composition (with large improvisational parts) that used several non-standard techniques. They began with a loud shout performed by both musicians, and suited by a very deep and complex net of instrumental and synthetic sounds. The second piece consisted entirely of nonharmonic sounds, all kinds and colors of noise worked and presented in balanced doses in order to make it violent but easy to listen to. It was surprising that the Morelian audience, who rarely hears non-traditional sounds in concert halls, was very attentive and vigorously applauded the work of Presidentes con Bigote.

Two performances were particularly interesting in this festival: one was the Japanese-Irish group called Ibitsu and the other was Kinesthetech Sense, an American duo that masters equally the computer processes of sound and video, the use of instruments and the consciousness of the scene through dance and movement.

Ibitsu performed a piece named Hystère for an especially innovative instrument they created themselves called the "E-clambone," which is a technological hybrid of clarinet and trombone that uses a saxophone mouthpiece. Hystère consists of mostly improvised music for the E-clambone with a real-time computer music and video counterpart that responds to the music, but in a non-linear way so that it's not predictable and easily holds the attention of the audience. While Satoshi Shiraishi on his E-clambone and Alo Allik on the computer create an inner and contemplative sound design, Yota
Morimoto gets the view of a camera set in front of the stage, transforms it using both video and sound information, and outputs the result in a screen set behind the stage.

In my opinion, Ibitsu has attempted the right balance between music and sound, between viewing and hearing, and - maybe the most difficult challenge of all - between balancing the artistic guidance of the audience and the unpredictable changes that make the entire piece something you want to keep watching and hearing.

Kinesthetech Sense performed in the same concert a work called The Color of Waiting, in which they used a video projected on a non-continuous screen in whose "holes" were set the cellist and the dancer. The Color of Waiting is truly a multimedia work - not just a juxtaposition of different media works (for example, a musical piece with a video added or with choreography added), but a work in which the parallel development of dance, video, instrumental and computer music is obvious. And there's still another field of artinvolved in thiscreation: the video part is made out of the design of a graphic artist which is "sliced," and the alternation of these slices produces a particular sense of movement. As the image taken is a water design, the resultant movement of waves is neither the usual behavior of water nor a computer emulation of that movement, but something that deals with the audience's time perception.
The NWEAMO festival in Morelia was a surprising contemporary art (not just music) event that people from Morelia and visitors enjoyed and profited from. It is now up to the Mexican artistic community to continue with these kinds of festivals and to expand the research of technological applications in art in order to create a truly contemporary Mexican art. 


\section{The Future of the \\ Concert Review}

by Jennifer Bernard Merkowitz, Co-Editor

In our last issue (Winter 2006, p. 43), we published an article by Leigh Landy entitled "Why Haven't I Written about the Pieces Played at ICMC?" In his article, Landy questioned the usefulness of reviews of "one-off events." Many of the pieces performed at the ICMC are new works that are not easy to come by Generally, only the people who attended the concert have had the opportunity to hear them. Subsequent hearings - which are necessary to fully appreciate any type of music, and especially music that is presented at an ICMC-are difficult, if not impossible. Chances are that if you have been reading this issue of Array from the beginning, you have already complained that the pieces discussed in the reviews are either distant memories or completely unknown to you.

Landy also lamented the practice of what he terms "Mutual Back Patting" in many ICMC reviews. The author of the review engages in little more than technical explanations, polite encouragement, and deliberately vague language. Lacking is an actual assessment of the success of the work from an aesthetic standpoint.

I am happy to say that many of the reviews published in this issue do attempt to grapple with the issue of the composer's intent and a piece's ability to hit the mark. However, there still remains a fair bit of blow-by-blow commentary and program note paraphrasing that gets passed off as serious reviewing, and Array is not the only place that such reviews appear. This phenomenon is woefully present in many realms of the new music world. Are we afraid that being frank about our colleagues' work will hurt their self-esteem? Or are we afraid that someone else might look at our own work with a similarly critical eye? Are we - composers, performers, and engineers dedicated to the development, promotion and appreciation of computer music - doing ourselves any favors by not speaking our minds about what moves us? No, we are not.

Array is certainly not equipped to solve this entire crisis of reception on our own, but we'd like to attempt to make our own reviews more relevant to our readers. So how do we solve these problems? There are two main issues: the first is the problem of enabling repeat hearings, and the second is the lack of honest and intelligent debate. In his article, Landy wished to see "active musical debate (and distribution) replace the review until the status of appreciation has been improved." With the release of ICMA's new website, we hope to come closer to that goal.

Margaret Schedel, Toine Heuvelmans, Jeffrey Treviño and I (along with a few others) have been discussing the best way to use the website to enable a "hyper-print" version of Array to exist - one that, while not eschewing the "traditional" printed reviews, enables repeat listening of select pieces and the capacity to discuss them online. The role of the "reviewer," then would not be someone who jots down notes on his or her program booklet and types them up a week (or a month, or six months) later, but someone whose role is more like that of a moderator who leads a discussion board and summarizes the discussion afterward in printed format The printed review would contain a link to the discussion, enabling interested reader of Array to listen to the piece and contribute to further discussion. We could not do this, of course, without the permission of the artists involved; while some might be enthusiastic to distribute their piece to wider audience, others might be hesitant for any number of good reasons. This might be solved by adding a checkbox to future ICMC submission forms that lets artists choose whether they give ICMA the right to post their submitted piece on the website. Discussion could still take place about pieces without online documentation. If all goes well, we could extend the format to deal with other events posted by members on the website.

Before we roll out such a system, however, we'd like to get your opinion. Do you read the reviews in Array as they currently stand? Do you think it is a good idea to have an online discussion forum available for each ICMC concert? Would you actually participate in these forums if they existed? Do you think we should dispense with written reviews, or do you think that no amount of online discussion can replace the written review? Would you agree to have your work(s) exist in some form on the ICMA website? Please direct your comments to array.journal@gmail. com. We will take them into account when the board discusses the future direction of Array. We look forward to hearing from you. 